\title{
Chemistry-climate model SOCOL-AERv2-BEv1 with the cosmogenic Beryllium-7 isotope cycle
}

\author{
Kseniia Golubenko ${ }^{1}$, Eugene Rozanov ${ }^{2,3,4}$, Gennady Kovaltsov ${ }^{5}$, Ari-Pekka Leppänen ${ }^{6}$, \\ Timofei Sukhodolov ${ }^{2,3,4}$, and Ilya Usoskin ${ }^{1,7}$ \\ ${ }^{1}$ Space climate research unit, University of Oulu, Oulu, 90570, Finland \\ ${ }^{2}$ Physikalisch-Meteorologisches Observatorium Davos and World Radiation Center, Davos Dorf, 7260, Switzerland \\ ${ }^{3}$ Institute for Atmospheric and Climate Science, ETH Zurich, Zurich, 8092, Switzerland \\ ${ }^{4}$ Faculty of Physics, St. Petersburg State University, St. Petersburg, 198504, Russia \\ ${ }^{5}$ Ioffe Physical-Technical Institute, St. Petersburg, 194021, Russia \\ ${ }^{6}$ Radiation and Nuclear Safety Authority - STUK, Rovaniemi, 96400, Finland \\ ${ }^{7}$ Sodankylä Geophysical Observatory, Sodankylä, Oulu, 99600, Finland
}

Correspondence: Kseniia Golubenko (kseniia.golubenko@oulu.fi)

\begin{abstract}
Short-living cosmogenic isotope ${ }^{7} \mathrm{Be}$, produced by cosmic rays in the atmosphere, is often used as a probe for atmospheric dynamics. Previously, modelling of the beryllium atmospheric transport was performed using simplified box-models or air back-tracing codes. While the ability of full atmospheric dynamics models to model beryllium transport was demonstrated earlier, no such ready-to-use model is currently available. Here we present the chemistry-climate model SOCOL-AERv2-BEv1 to trace isotopes of beryllium in the atmosphere. The SOCOL (SOlar Climate Ozone Links) model has been improved by including modules for the production, deposition, and transport of beryllium. Production was modelled considering both galactic and solar cosmic rays, by applying the CRAC (Cosmic-Ray induced Atmospheric Cascade) model. Radioactive decay of ${ }^{7} \mathrm{Be}$ was explicitly taken into account. Beryllium transport was modelled without additional gravitational settling due to the small size of the background aerosol particles. An interactive deposition scheme was applied including both wet and dry depositions. The modelling was performed, using a full nudging to the meteorological fields, for the period of 2003-2008 with a spin-up period of 1996-2002. The modelled concentrations of ${ }^{7} \mathrm{Be}$ in near-ground air were compared with the measured, at a weekly cadence, ones in four nearly antipodal high-latitude locations, two in Northern (Finland and Canada) and two in Southern (Chile and Kerguelen Island) hemispheres. The model results agree with the measurements in the absolute level within error bars, implying that the production, decay and lateral deposition are correctly reproduced by the model. The model also correctly reproduces the temporal variability of ${ }^{7} \mathrm{Be}$ concentrations on the annual and sub-annual scales, including a perfect reproduction of the annual cycle, dominating data in the Northern hemisphere. We also modelled the production and transport of ${ }^{7} \mathrm{Be}$ for a major solar energetic-particle event of 20-Jan-2005. Concluding, a new full 3D time-dependent model, based on the SOCOL-AERv2, of beryllium atmospheric production, transport and deposition has been developed. Comparison with the real data of ${ }^{7} \mathrm{Be}$ concentration in the near-ground air fully validates the model and its high accuracy.
\end{abstract}


https://doi.org/10.5194/gmd-2021-56

Preprint. Discussion started: 7 April 2021

(c) Author(s) 2021. CC BY 4.0 License.

(c) (i)

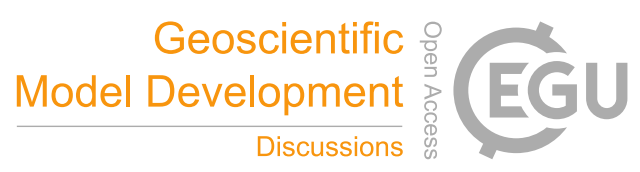

\section{Introduction}

One of the most important outer-space factors affecting Earth is related to cosmic rays (highly energetic nuclei of extraterrestrial origin), which cause nucleonic-electromagnetic-muon cascade in the terrestrial atmosphere (Dorman, 2004). These cosmic-ray induced atmospheric cascades form the main source of ionization in the troposphere and stratosphere (e.g., Mironova et al., 2015). Nuclear interactions between the nucleonic component of the cascade and nuclei of atmospheric gases such as nitrogen and oxygen can produce radioactive nuclides (Lal and Peters, 1967; Beer et al., 2012) including ${ }^{7}$ Be (half-life 53.22 days) and ${ }^{10} \mathrm{Be}$ (half-life $1.4 \cdot 10^{6}$ years). Since this is the dominant source of these nuclides in the terrestrial system, they are called cosmogenic isotopes.

Production rates of beryllium isotopes vary in time following the intensity of galactic cosmic rays (GCR) modulated by solar magnetic activity (the 11-year solar cycle), geomagnetic field strength and sporadic events of solar energetic particles (SEPs) (see, e.g., Usoskin and Kovaltsov, 2008; Kovaltsov and Usoskin, 2010). Concentrations of cosmogenic isotopes can be measured (via $\gamma$-spectrometry or acceleration mass spectrometry) directly in the air or precipitating water or in natural stratified archives such as live or dead trees, ice core or sediments (e.g., Beer et al., 2012). In particular, long-living ${ }^{10} \mathrm{Be}$ recorded in polar ice cores is one of the main proxies for long-term solar-activity reconstructions in the past (e.g., Steinhilber et al., 2012; Wu et al., 2018). However, there is a complicated process, which may significantly affect the relationship between the production of the isotope and its content in the measured samples. It is related to the transport of beryllium in the atmosphere and its deposition on the surface or into the medium where it is measured.

Studies of short-living ${ }^{7} \mathrm{Be}$ isotope and its ratio to ${ }^{10} \mathrm{Be}$ provide a precise way to probe large scale atmospheric dynamical properties and validate the corresponding atmospheric models (e.g., Raisbeck et al., 1981; Jordan et al., 2003; Ioannidou and Paatero, 2014). For the long-living ${ }^{10} \mathrm{Be}$ isotope, different transport/deposition assumptions and models were used (e.g., McCracken, 2004; Heikkilä et al., 2009; Sukhodolov et al., 2017; Usoskin et al., 2020a). However, these models cannot be applied for the short-living ${ }^{7} \mathrm{Be}$ isotope, whose half-life time is shorter than the typical atmospheric transport time.

The ability of a full atmospheric-dynamic model to catch the pattern of beryllium transport and deposition event at regional spatial and synoptic temporal scales was demonstrated by Usoskin et al. (2009a), who modelled concentrations of ${ }^{7} \mathrm{Be}$ isotope in different locations using the Goddard Institute for Space Studies (GISS) atmospheric circulation Model (Field et al., 2006) with full nudging for January - February 2005 and compared them with measurements. The agreement was very good confirming the validity of the model.

A full 3D modelling of the production and transport of beryllium isotopes in the Earth's atmosphere was performed earlier using the ECHAM5-HAM atmospheric model (Heikkilä et al., 2008a,b).

A simplified 2D model for beryllium stratospheric sedimentation was developed by Delaygue et al. (2015) but also not

supported further. Accordingly, transport of ${ }^{7} \mathrm{Be}$ is typically considered with a very simple box-reservoir exchange model (e.g., Pacini et al., 2015; Zheng et al., 2021) or air-mass tracing codes (Pacini et al., 2011; Brattich et al., 2020). The latter approach is applicable only to recent years where the wind field is known. 
https://doi.org/10.5194/gmd-2021-56

Preprint. Discussion started: 7 April 2021

(c) Author(s) 2021. CC BY 4.0 License.

\section{(c) (i)}

Thus, while several models of different complexity and accuracy have been developed in the recent past to model transport and deposition of beryllium isotopes, most of them have been abandoned and not supported further and cannot be directly applied in new analysis works. A full working model able to simulate production, transport and deposition of cosmogenic isotopes of beryllium from all sources, including realistic estimates of the uncertainties, particularly in the past, when direct nudging to the meteorological re-analysis data is not possible, is presently missing. Of special importance is a validation of models with available datasets of beryllium isotope concentration in situ and in archives.

Here we present a new development of the full chemistry-climate model (CCM) SOlar Climate Ozone Links (SOCOL)

60 for modelling of production, transport and deposition of the cosmogenic isotopes of beryllium as well as its validation with the available measurements. The SOCOL model was applied to an analysis of ${ }^{10} \mathrm{Be}$ for the strong SEP event of 23-Feb-1956 (Usoskin et al., 2020a), but its application for ${ }^{7}$ Be has not been checked. We have further upgraded the CCM SOCOL-AERv2 (Feinberg et al., 2019) by adding the the production, transport, and deposition of ${ }^{7} \mathrm{Be}$ and ${ }^{10} \mathrm{Be}$ isotopes from both GCR and SEP origins, considering stratosphere-troposphere exchange with high accuracy of $<10 \%$. Here we present a first systematic modelling of beryllium-isotope transport and deposition in the atmosphere for the years 2003-2008, using CCM SOCOL v3.0. This model set forms a methodological basis for a detailed study of the atmospheric dynamic and cosmogenic isotope distribution in the terrestrial system. The model computations were performed with full nudging to the observed meteorological data to verify the correctness of the model to trace beryllium isotopes. The model computations are directly compared with measurements of ${ }^{7} \mathrm{Be}$ isotopes in different high-latitude location to validate the model.

The paper is organized as follows: The model is described in Section 2; Obtained results are discussed in Section 3; Validation of the model by means of comparisons with measurements is presented in Section 4; Section 5 summarizes conclusions of the paper.

\section{Model description}

We used an extended version of the CCM SOCOLv3 (Stenke et al., 2013) with the sulfate aerosol module - SOCOL-AERv2 (Feinberg et al., 2019). This version consists of the general circulation model MA-ECHAM5 (Hommel et al., 2011), the atmospheric chemistry module MEZON (Egorova et al., 2003) combined with an sulfate aerosol module AER (Weisenstein et al., 1997), interacting with each other every two modelling hours. The chemical part of the MEZON core includes 87 chemical species of oxygen, hydrogen, nitrogen, carbon, chlorine, bromine and sulfur groups, 295 gas-phase reactions, 64 photolysis reactions, and 16 heterogeneous reactions on stratospheric aqueous sulfuric acid aerosols as well as three types of polar stratospheric clouds (PSCs). SOCOL uses the horizontal resolution T42, where $T$ refers to triangular truncation and the number denotes the series of spherical harmonics. The horizontal resolution is about $2.8^{\circ} \times 2.8^{\circ}(\approx 300 \times 300 \mathrm{~km}$ in the equatorial region). The vertical grid is defined using a sigma-hybrid coordinate system, which is calculated by a linear combination of surface pressure and constant coefficients that define the vertical coordinate. The model has 39 vertical levels between the Earth's surface and the $0.01 \mathrm{hPa}$ level $(\approx 80 \mathrm{~km})$. The aerosol module exploits a sectional microphysical scheme where the aerosol particle size distribution is represented by 40 discrete size bins. The model simulates the advective transport 
https://doi.org/10.5194/gmd-2021-56

Preprint. Discussion started: 7 April 2021

(c) Author(s) 2021. CC BY 4.0 License.
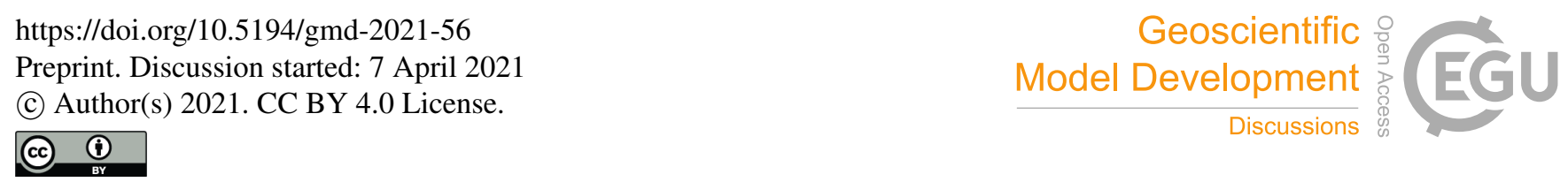

of stratospheric aerosol by the Brewer-Dobson large-scale circulation (Butchart, 2014) and gravitational sedimentation. We have made some modifications of the main model to focus on cosmogenic isotopes, as described below.

\subsection{Production rates of ${ }^{7} \mathrm{Be}$}

Production of beryllium isotopes was computed using the CRAC:Be (Cosmic-Ray Atmospheric Cascade: application to Beryllium) model (Poluianov et al., 2016) which is the most recent and accurate model of cosmogenic isotope production. This model simulates, using the GEANT4 (Geant4 collaboration, 2020) Monte-Carlo simulation tool, the full nucleonic-muonelectromagnetic cascade, induced by primary cosmic-ray particles in the atmosphere. This model is an essential upgrade of the previous versions of the CRAC:Be model (Usoskin and Kovaltsov, 2008; Kovaltsov and Usoskin, 2010) based on the CORSIKA simulation tool (Heck et al., 1998). The CRAC model presents a set of accurately computed yield functions of production of the cosmogenic isotopes for different primary particle's types, energy and atmospheric depths. By a numerical integration, above the local geomagnetic rigidity cutoff (Cooke et al., 1991), of the product of the yield function and the known (or assumed) energy spectrum of primary cosmic rays (of either Galactic or solar origin), one can obtain the isotope's production rate as function of location (via the geomagnetic rigidity cutoff), atmospheric height (via the yield function) and time (via the time-variable energy spectrum). These production rates, computed for each location and with hourly temporal cadence, were used as an input for the SOCOL model, providing a 3D+time source of the isotope in the atmosphere.

Production due to Galactic cosmic rays (GCR) which always bombard the Earth with slightly variable intensity due to solar modulation was computed by applying the force-field model (Gleeson and Axford, 1968) with the modulation potential reconstructed from the world neutron-monitor network (Usoskin et al., 2017). Geomagnetic field was taken according to the International Reference Geomagnetic Field (IFRG, Thébault et al., 2015) in the eccentric dipole approximation (FraserSmith, 1987; Usoskin et al., 2010). While GCR are always present near Earth, sporadic solar particle events (SPEs) take place occasionally (Vainio et al., 2009; Desai and Giacalone, 2016), which can be sufficiently strong to be recorded by ground-based neutron monitors (Raukunen et al., 2018; Usoskin et al., 2020b). A large amount of cosmogenic isotopes can be produced during such events (Usoskin et al., 2020a). To model the contribution of severe SPEs, we modelled the production of beryllium by SPE of 20-Jan-2005 (GLE \#69), which was the strongest event during the studied period and the second strongest directly observed. The same yield function and geomagnetic cutoff approach, as for GCR, were applied along with the SEP energy spectrum obtained for this event by Usoskin et al. (2020b). To study the effect of seasonality on the beryllium transport we simulated the SEP event to occur not only on its actual date in mid-winter (20-Jan-2005) but also mid-spring, summer and autumn (20-Apr, 20-Jul and 20-Oct of 2005, respectively).

Figure 1 shows ${ }^{7} \mathrm{Be}$ zonal mean production rate as a function of the atmospheric pressure and northern geographical latitude from two sources: GCR (panel A) and SPE (panel B). Since the production of beryllium is nearly symmetric between the global hemispheres, as defined by the geomagnetic shielding, only the Northern hemisphere is shown. Even though the production rate is significantly higher in the polar region, its contribution to the global production is not dominant, because of the small area of the polar regions. For the GCR-related production, the dominant production region is located in the mid-high latitude $\left(40-70^{\circ}\right)$ stratosphere and upper troposphere (above $400-\mathrm{hPa}$ level or $\approx 7 \mathrm{~km}$ ). Production of beryllium by SEPs is confined 


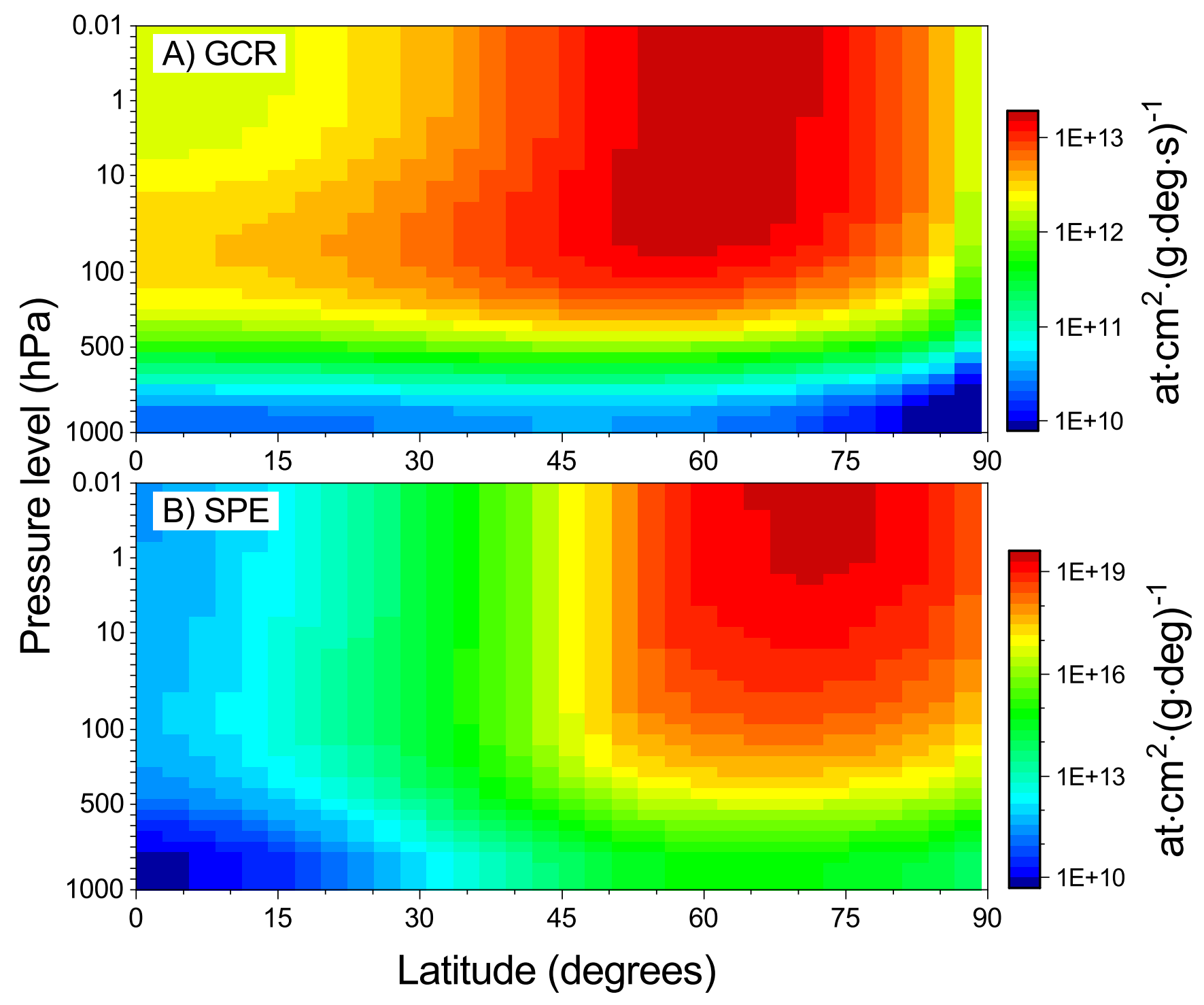

Figure 1. Zonal mean production rates of ${ }^{7} \mathrm{Be}$ in the Northern hemisphere as a function of geographical latitude and model's atmospheric pressure level. Panel A: production by GCR averaged over the period of $2002-2008$. The colour scale (on the right) is given in units of atoms per second per degree of latitude per $\mathrm{g} / \mathrm{cm}^{2}$. Panel B: Total production by SPE of 20-Jan-2005. The colour scale is in units of atoms per degree of latitude per $\mathrm{g} / \mathrm{cm}^{2}$. Notice the difference in scales between panel A and B.

to the polar (latitude $>55^{\circ}$ ) upper stratosphere and mesosphere (above 50-hPa level or $\approx 35 \mathrm{~km}$ ). Hardly any beryllium is produced by SEPs in the tropical region. In all cases, the maximum of production lies at mid-/high-latitudes in the stratosphere and the production rate decreases towards the surface, because of the increasing atmospheric depth, and equator due to the 
https://doi.org/10.5194/gmd-2021-56

Preprint. Discussion started: 7 April 2021

(c) Author(s) 2021. CC BY 4.0 License.

(c) (i)

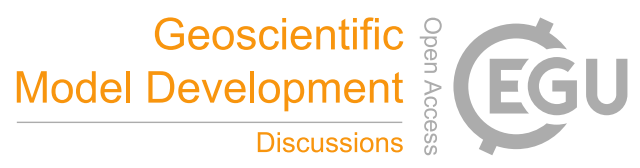

geomagnetic shielding. Due to the much softer energy spectrum, SEPs produce beryllium at shallower atmospheric depths and higher latitudes than GCR do.

\subsection{Decay of ${ }^{7} \mathrm{Be}$}

${ }^{7} \mathrm{Be}$ is a short-living isotope whose decay cannot be neglected because its life-time is shorter than the typical transport/deposition time, in contrast to long-living ${ }^{10} \mathrm{Be}$ isotope. Accordingly, a standard decay probability of $0.054 \%$ per hour (corresponding to the isotope's mean half-life of 53.22 days) was applied during tracing of ${ }^{7} \mathrm{Be}$ in a way similar to that used by Golubenko et al. (2020) for ${ }^{222} \mathrm{Rn}$. No decay needs to be applied to ${ }^{10} \mathrm{Be}$ for this kind of modelling. Figure 2 shows the modelled global content of the two beryllium isotopes in the atmosphere after an instant production by the SPE event of 20-Jan-2005 (day zero). One can see that the amount of ${ }^{10} \mathrm{Be}$ decreases exponentially reflecting a slow removal of the isotope through precipitation. A typical time of the isotope removal is $\tau_{10 \mathrm{Be}}=550 \pm 100$ days, implying the residence time of $1-2$ years (cf., e.g., Beer et al., 2012). The decrease of ${ }^{7} \mathrm{Be}$ isotope concentration is much faster and nearly perfectly exponential with $\tau_{7 \mathrm{Be}}=72 \pm 3$ days, which includes both decay and the removal. Since the removal process is assumed to be identical for both isotopes, the concentrations of ${ }^{10} \mathrm{Be}$ can be used to correct for the system effects. The decay time of ${ }^{7} \mathrm{Be}$, estimated in this way, appears $1 / \tau=1 / \tau_{7 \mathrm{Be}}-1 / \tau_{10 \mathrm{Be}}$ as $\tau=82 \pm 4$ days which is consistent with the expected e-folding lifetime of ${ }^{7} \mathrm{Be}$ of 77 days, implying that the decay was accounted correctly in the model. Thus, the ${ }^{7} \mathrm{Be}$ isotope is fully removed from the atmosphere, mostly due to decay, within one year.

\subsection{Transport of cosmogenic isotopes ${ }^{7} \mathrm{Be}$ and ${ }^{10} \mathrm{Be}$}

After production, beryllium atoms are attached to ambient aerosols for transport and deposition processes. This process is modelled in SOCOL in such a way that beryllium is considered as a gas tracer without additional gravitational settling due to the small size $(0.5-1 \mu \mathrm{m}$, see Ioannidou and Paatero, 2014) of the beryllium-carrying background aerosol particles. Different processes such as stratospheric mixing, stratosphere-troposphere exchange (STE), tropospheric transport and deposition, are realistically modelled by the CCM SOCOL (Feinberg et al., 2019). In this study, the advective transport of beryllium isotopes in gas form was performed using Flux-Form Semi-Lagrangian Transport Schemes (Lin and Rood, 1996) embedded in ECHAM5.

\subsection{Deposition of the beryllium isotopes}

Dry deposition is typically modelled using a simplified approach that assumes constant dry deposition velocities over land and ocean, without accounting for seasonal or geographical variability. The tropospheric washout of gases is calculated by using a constant removal rate, irrespective of precipitation occurrence (Hauglustaine et al., 1994). SOCOL-AERv2 employs a more sophisticated scheme based on the surface resistance approach for the estimation of dry deposition velocities (Wesely, 1989). Deposition of beryllium isotopes is parameterized as a function of surface properties, solubility and reactivity of the considered species (Kerkweg et al., 2006). This scheme considers actual meteorological conditions, different surface types, and trace gas properties like solubility and reactivity. Since beryllium is transported like a gas in the CCM SOCOL, the dry- 


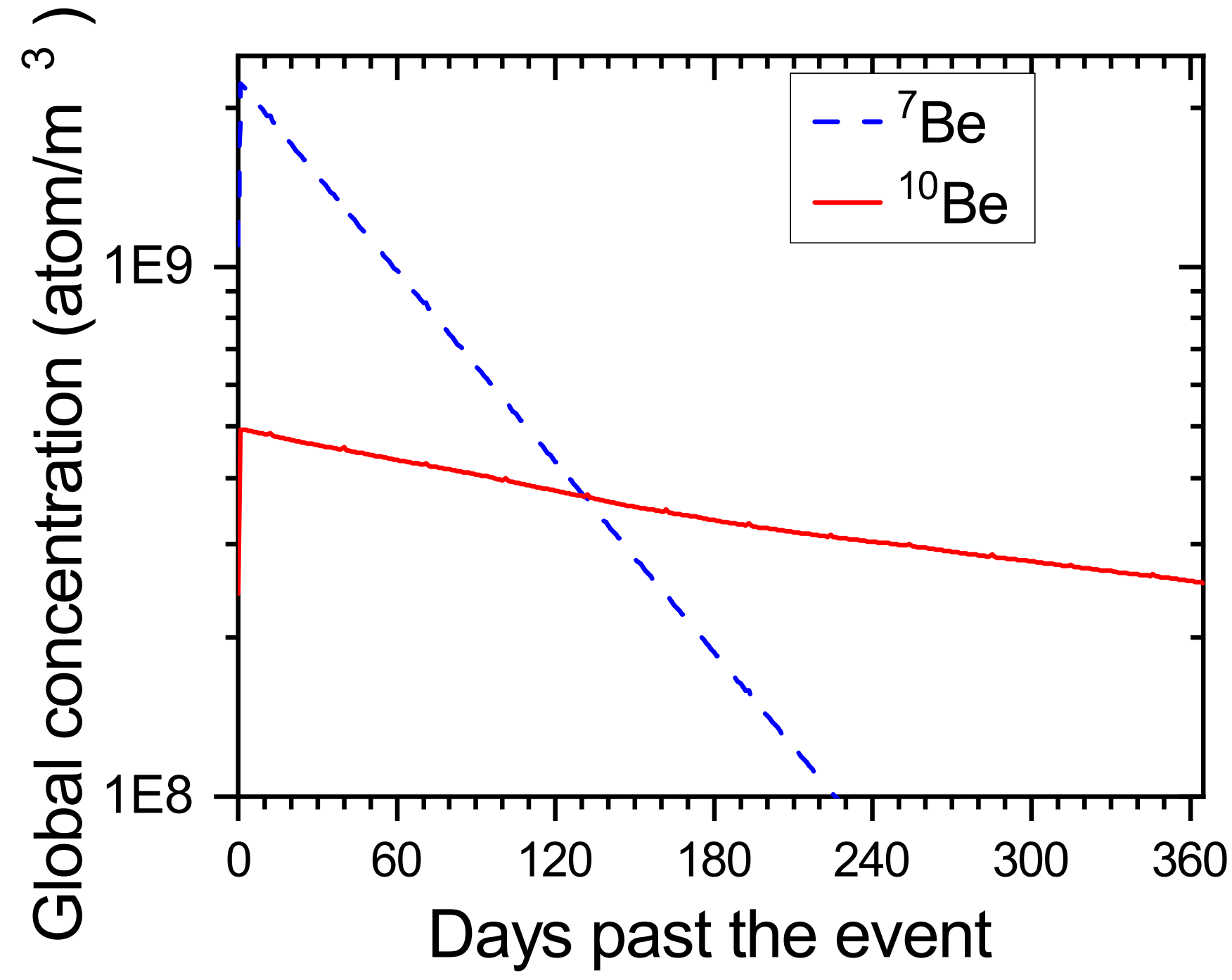

Figure 2. Computed global mean concentration of two beryllium isotopes, ${ }^{7} \mathrm{Be}$ and ${ }^{10} \mathrm{Be}$, produced by SPE of 20 -Jan-2005 (day zero) as function of time. The nearly exponential decay of concentration $\left(\tau=550 \pm 100\right.$ days and $72 \pm 2$ days for ${ }^{10} \mathrm{Be}$ and ${ }^{7} \mathrm{Be}$, respectively) includes both decay and sink (deposition) of the isotopes.

deposition scheme is similar to other gases in the model (e.g., Revell et al., 2018). Moist convection contributes significantly to transport of energy, momentum, water, and trace gases in global modelling. Since convective clouds are on a scale too small to be resolved in a global model their effects need to be parameterized. The interactive wet deposition scheme used in CCM SOCOL-AERv2 exploits the EAYSY2 version the Scavenging (SCAV) submodule in the ECHAM/MESSy Atmospheric Chemistry (EMAC) model (Tost et al., 2010). This scheme utilize ECHAM5 variables such as liquid and ice water contents, 
https://doi.org/10.5194/gmd-2021-56

Preprint. Discussion started: 7 April 2021

(c) Author(s) 2021. CC BY 4.0 License.

(c) (i)

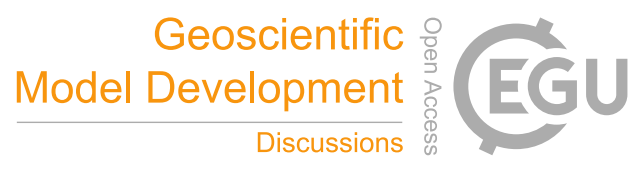

cloud cover, convective and large-scale rain, ice formation, precipitation fluxes, and convective upward mass flux. Scavenging coefficients for gas-phase species are calculated based on Henry's law equilibrium constants.

\subsection{Setup of numerical experiments}

Since ${ }^{10} \mathrm{Be}$ is removed from the stratosphere via the stratosphere-troposphere exchange (STE), and the stratospheric mixing time is long (about 2-3 years), we have performed a 6-year spin-up of the model for the period $1996-2001$ to allow ${ }^{10} \mathrm{Be}$ to reach equilibrium conditions. For ${ }^{7} \mathrm{Be}$, such a long spin-up is not needed since it is mostly removed from the atmosphere by decay, but we kept it similar to ${ }^{10} \mathrm{Be}$ for consistency. After the spin-up period, we initiated a 7-year $(2002-2008)$ run with full nudging (a linear relaxation of thermodynamic parameters: temperature, divergence and vorticity of the wind field). In this way, we can validate the model by comparing the results with measurements.

\section{Modelling results}

\subsection{Global patterns of ${ }^{7} \mathrm{Be}$ transport and deposition}

Figure 3 shows the zonal mean concentration of ${ }^{7}$ Be averaged over the Boreal summer and winter times for $2002-2008$, as modelled here. While the isotope production is symmetric between the hemispheres, the concentrations are not symmetric and depends on the large-scale dynamical patterns, which are different in the summer and winter hemispheres. The air circulation in the stratosphere is driven by a forcing from the breaking planetary and gravity waves. There are three circulation cells in each hemisphere. Tropical tropospheric air ascends into the stratosphere, while stratospheric air moves poleward and descends at middle and polar latitudes. Air descended from the stratosphere at mid-latitudes is transported back to the troposphere, but at the polar latitudes it resides quite long in the lower stratosphere (Cohen et al., 2014). The change of the beryllium concentration maximum from the polar regions during the colder season (Boreal summer for the southern hemisphere and winter in the northern hemisphere) is associated with the Brewer-Dobson circulation driving the beryllium transport in CCM SOCOL. Also, as expected, older ${ }^{7} \mathrm{Be}$-depleted air moves from the tropical stratosphere and troposphere towards the poles, during the cold seasons.

Figure 4 presents distributions of the total (wet and dry) deposition fluxes of ${ }^{7} \mathrm{Be}$ averaged over $2002-2008$. The deposition is low in arid regions, e.g., the Sahara and the Middle East. It is also low to the West of the continents, following the low precipitation above the cold ocean currents. The precipitation rate is the highest in the tropical convection zone due to the highest temperature gradients and strong convection in the equatorial area. The deposition, however, is not very high in low latitudes because both the production rate and the downward transport of beryllium are low in the tropics. It is important that gradients of the deposition can be strong even on the regional scale, suggesting that meteorological processes can strongly influence beryllium deposition at any given location (e.g., Usoskin et al., 2009b). This pattern agrees well with a similar previous study (Heikkilä et al., 2008b). 


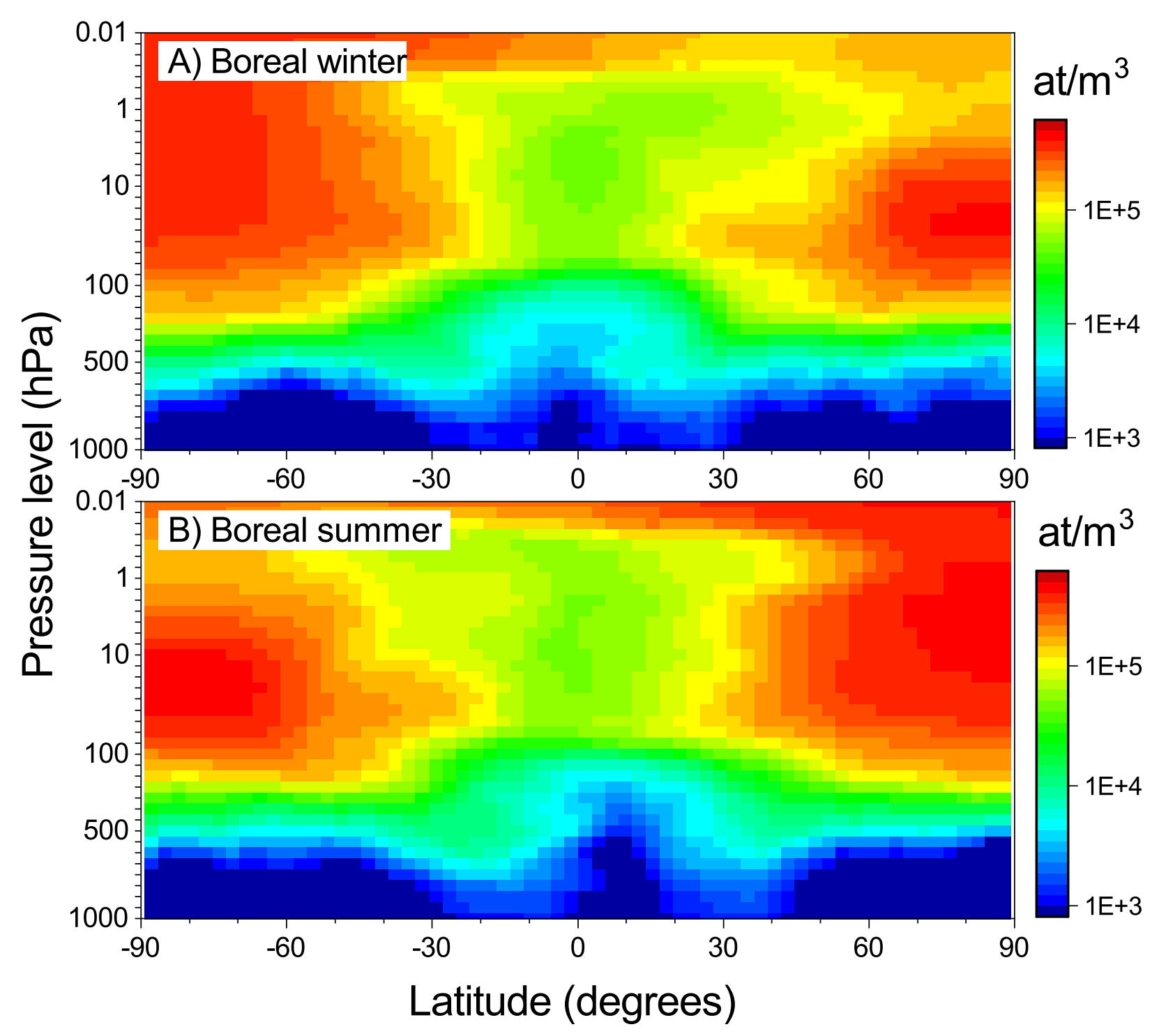

Figure 3. Modelled zonal mean concentrations of ${ }^{7}$ Be during the Boreal winter (panel A) and Boreal summer (panel B) seasons averaged over $2002-2008$.

\subsection{Beryllium isotope from a strong SPE}

While GCR always bombard the Earth's atmosphere with slightly variable intensity, major SPEs make a different impact, producing sporadic short (typically several hours) but very intense fluxes of energetic particles entering the atmosphere mostly in polar regions. Potentially, extreme SPEs, orders of magnitude stronger than those observed during the recent decades, can be recorded in cosmogenic isotope data (Usoskin et al., 2006; Usoskin et al., 2020a), and a proper model is needed to study them (Sukhodolov et al., 2017). Here, we modelled transport of such SPE-produced beryllium which was traced separately 


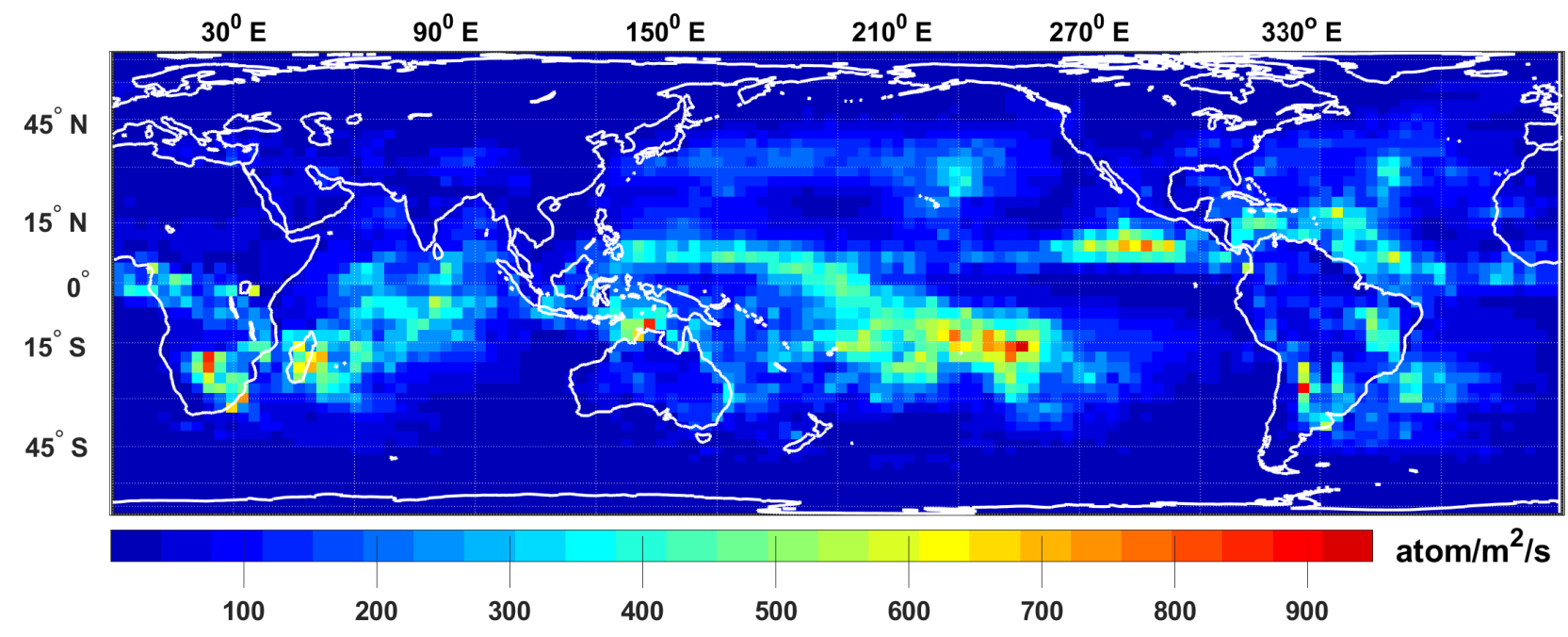

Figure 4. Lambert Equal-Area Cylindrical Projection map of ${ }^{7}$ Be total (wet and dry) deposition averaged over the period of $2002-2008$.

from the GCR-produced one to perform a detailed study, based on the SPE of 20-Jan-2005. In order to distinguish between different sources, we traced five beryllium tracers for the isotope: one for GCR-produced beryllium and four tracers for the SEP-scenarios as described above.

Production of the ${ }^{7} \mathrm{Be}$ isotope during this SPE (Figure 1B) appears mostly in the polar stratosphere and lower mesosphere. After production, the isotope starts decaying and being caught by the air dynamics. Figure 5 shows an example of the SPEproduced isotope concentration on the 30-th day after the event (19-Feb-2005). One can see that the production pattern has been already smeared by the transport, leading, in particular to an essential hemispheric difference. It is interesting that tropospheric concentrations are higher at mid/low latitudes around $30^{\circ}$ than in polar regions, because of the atmospheric circulation (i.e. increased stratosphere-troposphere coupling and large-scale downward motion in the troposphere). As an example, the modelled activity of ${ }^{7} \mathrm{Be}$ in near-ground air is shown in Figure 6 as averaged over Finland. The locally (polar troposphere) produced beryllium dominates during the first 20 days after the event, but then the transport starts playing a role, leading to the very low concentrations during the subsequent period. The level of activity for this event in the near-air in Finland is very low, a factor 100 lower than the typical level (around 900-1500 uBq/m3) of activity due to GCR during the winter season (see Figure 8A).

Although the SPE of 20-Jan-2005 was a very strong one, the second strongest directly observed, its imprint in cosmogenic isotopes is not detectable on the background of air-transport dynamic and GCR variability. An SPE must be stronger by a factor of ten or more than this one to become detectable in isotope records even on the daily scale (cf. Sukhodolov et al., 2017; Usoskin et al., 2020a). 


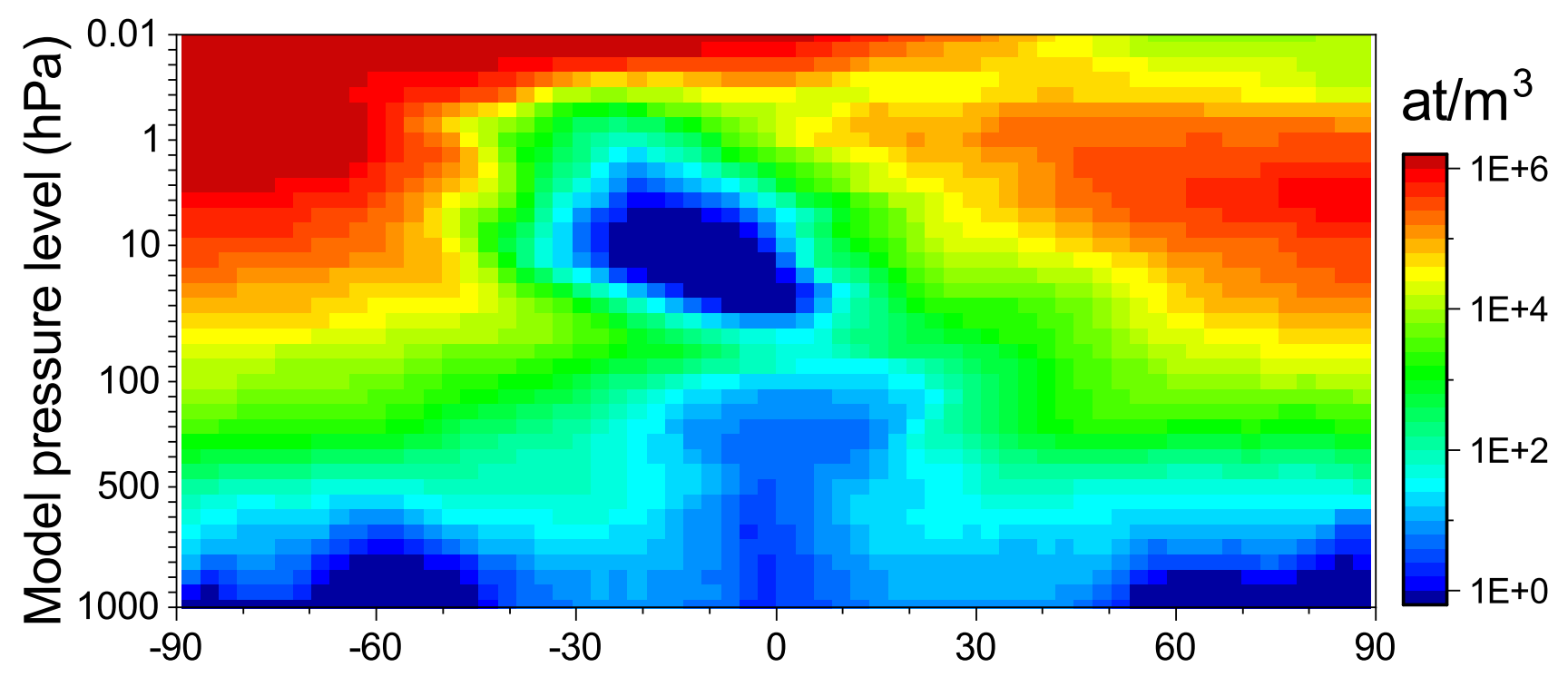

Figure 5. Distribution of the concentrations of ${ }^{7}$ Be produced by the SPE of 20-Jan-2005, on 19-Feb-2005, viz. 30 days after the event.

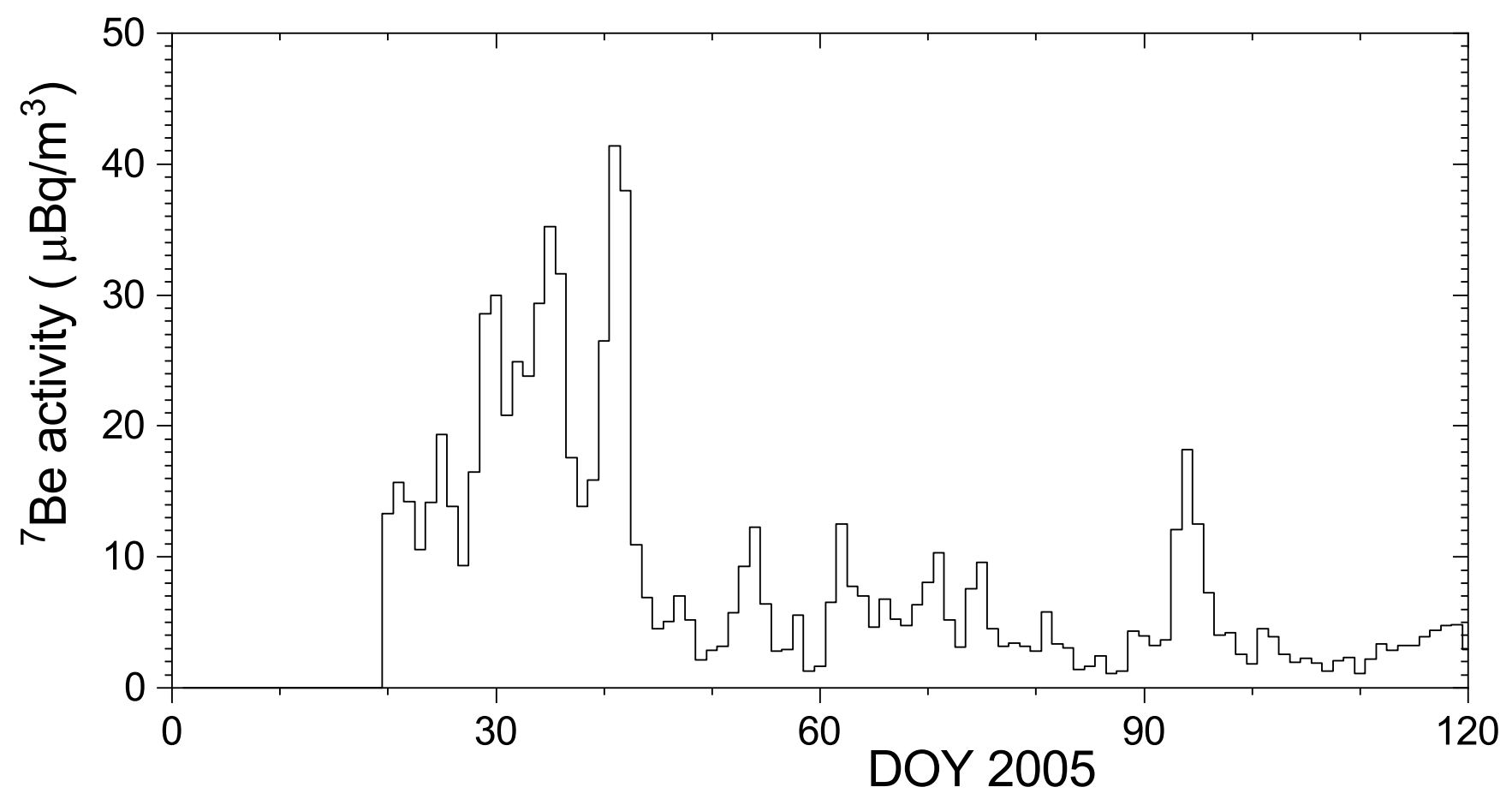

Figure 6. Modelled activity of ${ }^{7} \mathrm{Be}$, produced by the SPE of 20-Jan-2005, in near-ground air in Finland. 


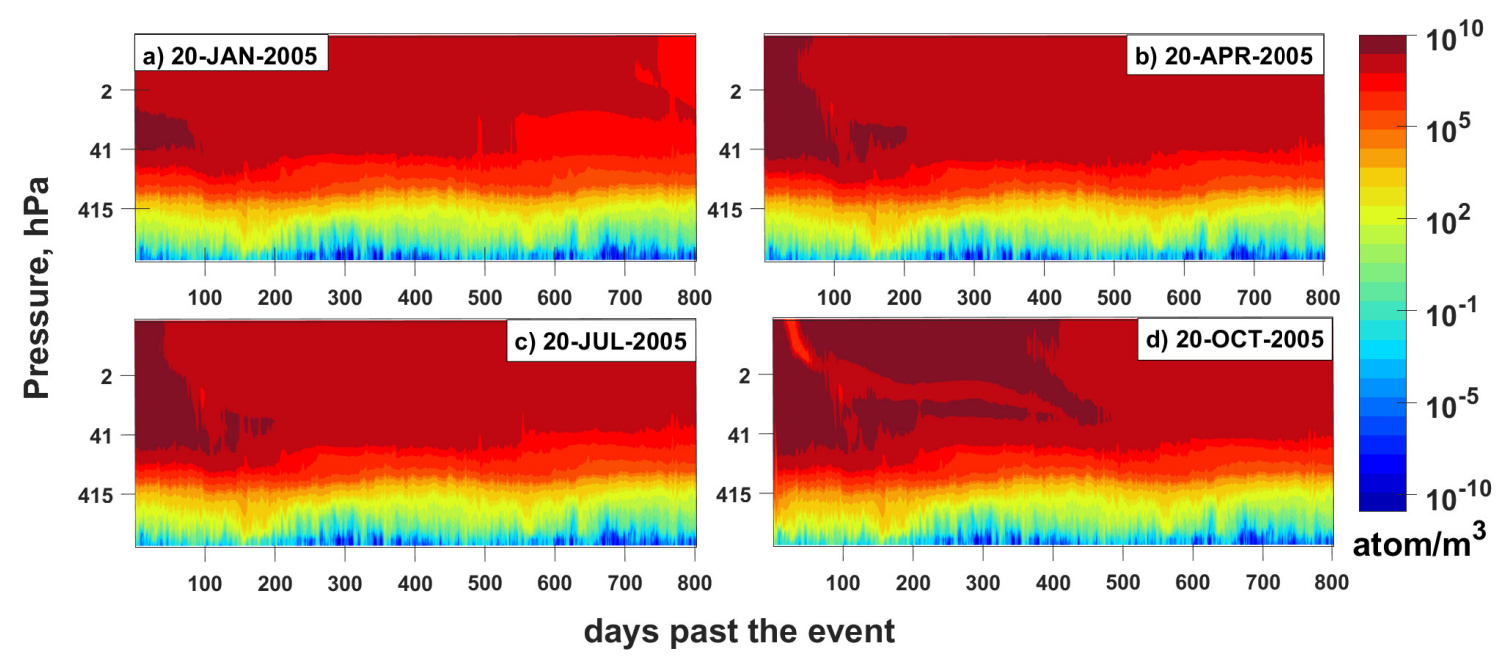

Figure 7. Polar (at $85^{\circ} \mathrm{N}$ latitute) mean concentration of ${ }^{10} \mathrm{Be}$ in northern hemisphere for SPE in different seasons.

The transport of beryllium after production may depend on the season. In order to study that, we simulated the same SPE of 20-Jan-2005 as if it occurred in mid-spring (20-Apr-2005), mid-summer (20-Jul-2005) and mid-autumn (20-Oct-2005).

215 Figure 7 shows the concentration of ${ }^{10} \mathrm{Be}$ in the northern hemisphere $\left(85^{\circ}\right.$ latitude) for the same modelled SPE but occurring during different seasons. Here we consider ${ }^{10} \mathrm{Be}$ because of the fast decay of ${ }^{7} \mathrm{Be}$ which smears the time variability of the concentration. The most pronounced and long-lasting effect occurs from the SPE taking place during the autumn (panel d) when a strong concentration of beryllium persist in the stratosphere region for about one year and gradually decreases after that for a few more years. The patterns of the SPE occurring during summer (panel c) and spring (panel b) seasons are similar to each other in that it has a shorter residence time (only a few months) and a smaller spread of beryllium. The winter scenario suggests somewhat faster removal of beryllium from the atmosphere, but it also stays in the upper atmosphere for several years. The concentration in near-ground air is mostly defined by the seasonal cycle and is consistent between different scenarios of the SPE occurrence date.

\section{Evaluation of the model by comparison with direct ${ }^{7}$ Be measurements}

225 In this section, we validate the model by comparing the simulation results with actual measurements of the near-ground-air ${ }^{7}$ Be concentration in air filters performed in Boreal and Austral high-latitude regions (Section 4.1), as shown in Figure 8. 
https://doi.org/10.5194/gmd-2021-56

Preprint. Discussion started: 7 April 2021

(c) Author(s) 2021. CC BY 4.0 License.

(c) (i)

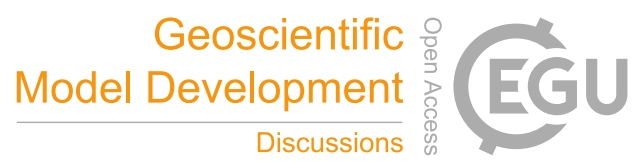

\section{1 $\quad{ }^{7}$ Be mesurements}

For the model verification, we used data of the measured activity (concentration) of ${ }^{7} \mathrm{Be}$ isotope in near-ground air, with weekly sampling rate (corrected for decay) performed in different hemispheres, for the period 2002-2008. Traditionally, for shortliving isotopes, the measured quantity is not atomic concentration but activity concentrations, in units of becquerel (number of radioactive decays per second) per a cubic meter of air $\left(\mathrm{Bq} / \mathrm{m}^{3}\right)$, as directly measured by a $\gamma$-spectrometer. Correction for decay is standardly performed. The activity and concentration can be easily translated to each other using the known life-time of the isotope.

Here we use data from four nearly antipodal high-latitude locations as described below. Two locations are in the Northern hemisphere: Finland (a set of stations) and Canada (Yellowknife); and two in the Southern hemisphere: Kerguelen island (French) and Punta Arenas (Chile). The longitudinal separation between the locations in each hemisphere is greater than $140^{\circ}$. The data series are shown in Figure 8 and described below.

Finnish data of the measured ${ }^{7} \mathrm{Be}$ activity were provided, for the period $2002-2008$, by the Finnish National Radiation and Nuclear Safety Authority (STUK) for four sites: Kotka $\left(60.28^{\circ} \mathrm{N} 26.56^{\circ} \mathrm{E}\right)$, Kajaani $\left(64.13^{\circ} \mathrm{N} 27.44^{\circ} \mathrm{E}\right)$, Rovaniemi $\left(66.3^{\circ} \mathrm{N}\right.$ $\left.25.44^{\circ} \mathrm{E}\right)$ and Ivalo $\left(68.39^{\circ} \mathrm{N} 27.33^{\circ} \mathrm{E}\right)$, spanning meridionally $8^{\circ}$ in latitude. The isotope of ${ }^{7} \mathrm{Be}$ was collected on air filters using a high-volume air sampler on a weekly basis, and then its activity was measured with an HPGe (High Purity Germanium) detector inside a 4-inch thick lead shielding in the STUK laboratory. The statistical measurement uncertainty is 3-5\%, see a detailed description of the sampling and measurement procedure in Leppänen et al. (2012). The data from the four stations were combined as the average of the four locations for each time interval, to represent a regional-scale dataset, as shown in Figure 8A.

${ }^{7} \mathrm{Be}$ data from the Yellowknife site (Canada, $62.47^{\circ} \mathrm{N} 114.47^{\circ} \mathrm{W}$ ) kindly provided by the Radiation Protection Bureau of Health Canada. The original data are with daily cadence, but have been combined into weekly samples (correction for decay applied) for consistency with other datasets. The dataset is shown in Figure 8B. The total uncertainty for the measured ${ }^{7} \mathrm{Be}$ activity is defined mostly by statistics and is approximately $7-8 \%$.

For the Southern hemisphere, we considered weekly ${ }^{7} \mathrm{Be}$ activities measured at Punta Arenas $\left(\mathrm{Chile}, 53.15^{\circ} \mathrm{S} 70.92^{\circ} \mathrm{W}\right.$, CTBT station code CLP18). During 2002 - 2006, the data contain many long breaks (about half of weekly data are missing), hence we considered data since October 2006 only, as shown in Figure 8C.

Another Southern Hemisphere station is located at Port-aux-Français, Kerguelen Island $\left(49.35^{\circ} \mathrm{S} 70.22^{\circ} \mathrm{E}, \mathrm{CTBT}\right.$ station code FRP30) with data available since 2006 (Figure 8D).

The data for Punta Arenas and Kerguelen Island were obtained via the virtual Data Exploration Centre (vDEC) of the Preparatory Commission for the Complete Nuclear Test-Ban-Treaty Organisation (CTBTO). A full description of the sampling and measurement of the CTBT data is available elsewhere (Miley et al., 1998; Medici, 2001).

In addition to ${ }^{7} \mathrm{Be}$ activity measured in near-ground air, we also exploited data on the quarterly total-deposition ${ }^{7} \mathrm{Be}$ measurements (without separating dry and wet depositions) measured in collected precipitation water at Rovaniemi and Ivalo stations, as provided by STUK and previously published in Leppänen (2019). The fallout sample collection period was one month, but 
https://doi.org/10.5194/gmd-2021-56

Preprint. Discussion started: 7 April 2021

(c) Author(s) 2021. CC BY 4.0 License.

(c) (i)

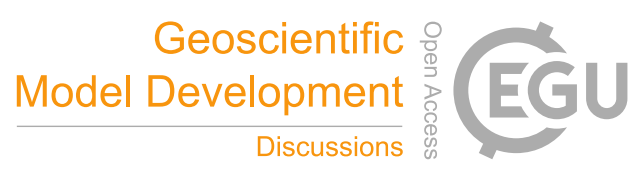

the three samples were combined together to form a quarterly sample. Hence, the four measured samples for each year cover period of January to March, April to June, July to September and October to December, respectively. The reference date was set to the middle of the sampling period (since the decay time of ${ }^{7} \mathrm{Be}$ is shorter than the sampling interval) and the activities were decay-corrected to this date (see Leppänen, 2019). The ${ }^{7}$ Be deposition averaged over the two locations is shown in Figure 9.

\subsection{Comparison between modelled and measured data}

First, we compared the modelled ${ }^{7} \mathrm{Be}$ activity with measured for the all-Finland record, compiled from four stations (see Section 4.1) as shown in Figure 8A. The linear Pearson correlation between the modelled and measured weekly series is highly significant $r=0.68 \pm 0.02$ ( $p$-value $<10^{-6}$ ). Figure 10A shows the global wavelet coherence, which is an analogue of the correlation coefficient but extending it into the frequency domain, between the modelled and measured ${ }^{7} \mathrm{Be}$ activities for the Finnish stations. The coherence is highly significant (confidence level above 95\%) at all time scales between one month and two years. Although there are discrepancies on the very short time scales, related to the synoptic noise, the model correctly reproduces some strong spikes in the beryllium activity, as e.g., in the earlier 2003, which are often related to sudden stratospheric warming (SSW) events (Pacini et al., 2015; Brattich et al., 2020). It is important that the long-term variability (at annual time scale) is correctly reproduced by the model. The overall mean (averaged over seven yearly values) level of the modelled activity $\left(2.05 \mathrm{mBq} / \mathrm{m}^{3}\right)$ is close to the measured one $\left(1.86 \mathrm{mBq} / \mathrm{m}^{3}\right)$, within $10 \%$ (the difference is $0.19 \pm 0.19$ $\mathrm{mBq} / \mathrm{m}^{3}$ ). The $z$-test suggests that this difference is insignificant. On the other hand, there is an essential difference between the model and the measurements regarding the magnitude of summer peaks in 2007 and 2008. It could be potentially related to the local atmospheric aerosol properties, but the AERONET (AErosol RObotic NETwork) (Emery and Camps, 2017) station in Sodankylä (Northern Finland) did not show any anomalies for that time.

For the Canadian station, the agreement between the modelled and measured activities (Figure 8B) is nearly perfect, including a correct reproduction of the very strong seasonal cycle and sudden short spikes, as, e.g., in late 2003. The Pearson correlation coefficient is $r=0.78 \pm 0.02\left(p\right.$-value $<10^{-6}$ ). The coherence between the simulated and measured datasets (Figure 10B) is highly significant at all time scales between one month and 1.5 years. The overall mean level of modelled activity $\left(2.15 \mathrm{mBq} / \mathrm{m}^{3}\right)$ is close to the measured one $\left(2.4 \mathrm{mBq} / \mathrm{m}^{3}\right.$ ), within $10 \%$ (the difference is $0.24 \pm 0.22 \mathrm{mBq} / \mathrm{m}^{3}$ ). The $z$-test suggests that the difference is insignificant. The most pronounced difference between the model and the measurements was observed in 2008 .

The Chilean data (Figure 8C) depicts a reasonable agreement between the model and the measurements. Since the data contains no seasonal pattern, as correctly reproduced by the model, the formal correlation is insignificant $r=0.06$. However, it is dominated by the short-term variability, while the wavelet coherence analysis (Figure 10C) suggests that the two datasets are significantly coherent at time scales longer than 3 months. The mean levels of the modelled and measured series agree nearly perfectly, within $2 \%$, viz. 1.74 vs. $1.71 \mathrm{mBq} / \mathrm{m}^{3}$ for the modelled and measured activities, respectively.

Data from the Kerguelen island (Figure 8D) also depicts a reasonable agreement, including correctly reproduced spikes. Similar to the Chilean data, the formal correlation is insignificant $r=0.06$, but the coherence (Figure 10D) is highly significant at monthly and annual time scales. The mean levels of the modelled and measured series are not well-matched, with the 

the peculiarity of this site which is located on a small island (about $100 \mathrm{~km}$ across) in the middle of the ocean, while the model grid (about $300 \times 300 \mathrm{~km}$ ) is too rough to catch the orography.

Therefore, we conclude that the model correctly (within 10\%) calculates the mean levels of beryllium concentration for both northern and southern high-latitude locations, at least for the locations where the orographic scale is comparable to the grid size but may have larger uncertainties for unresolvable spatial scales. It is important that the model correctly reproduces the seasonal variability or its absence as well as some sudden spikes, particularly during the late winter and spring seasons likely related to SSW events.

In addition to the concentration of ${ }^{7} \mathrm{Be}$ in near-surface air (expressed in measured activity), we also compared the beryllium deposition modelled by SOCOL with that measured in the Northern Finland, as shown in Figure 9. The agreement is very good: the average levels (183 and $188 \mathrm{~Bq} / \mathrm{m}^{2}$ for the modelled and measured data, respectively) agree within $2.5 \%$, the correlation is highly significant $\left(r=0.86_{-0.06}^{+0.04}, p<10^{-6}\right)$. However, the discrepancy can be significant for individual years. Thus, we conclude that the model reasonably well reproduces also the depositional flux of ${ }^{7} \mathrm{Be}$ on the yearly time scale.

\section{Conclusions}

A full 3D model of production, transport and deposition of cosmogenic beryllium isotopes in the atmosphere has been developed. The model named as SOCOL-AERv2-BEv1 is based on the chemistry-climate model SOCOL, specifically tuned for the best performance in tracing beryllium, and the CRAC production model. Realistic modelling of ${ }^{7} \mathrm{Be}$ isotope was performed for the years 2002-2008, with a 5-year model spin-up during 1996-2001. The measured weekly concentrations of ${ }^{7} \mathrm{Be}$ in near-ground air have been compared with the model results for four nearly antipodal mid/high-latitude locations, two in the Northern (Finland and Canada) and two in the Southern (Chile and Kerguelen Island) hemispheres. The model results generally agree well with the measurements at the absolute level within error bars, implying that the production, decay and lateral deposition are correctly reproduced by the model. However, a larger discrepancy was observed at the Kerguelen Island where the orographic scale is much smaller than the model grid size. The model correctly reproduces the temporal variability of ${ }^{7} \mathrm{Be}$ concentrations on the annual and sub-annual scales, including a perfect reproduction of the annual cycle, which dominates data in the Northern hemisphere, and the absence of this cycle in the Southern hemisphere. This fully validates the newly developed model to be able to correctly simulate the production, transport and deposition of ${ }^{7} \mathrm{Be}$ on the local/regional spatial and monthly/annual temporal scales. The modelled beryllium distribution is also in general agreement with earlier computations based on a similar approach.

We have also modelled the production and transport of ${ }^{7} \mathrm{Be}$ for a major solar energetic-particle event of 20-Jan-2005, which was one of the largest directly observed events. It is shown that an order of magnitude stronger event is needed to become observable in the beryllium data.

Concluding, a new full 3D time-dependent model, based on SOCOL-AERv2, of beryllium atmospheric production, transport and deposition has been developed and validated using directly measured data. The model is recommended to be used in studies 
https://doi.org/10.5194/gmd-2021-56

Preprint. Discussion started: 7 April 2021

(c) Author(s) 2021. CC BY 4.0 License.

(c) (i)

related to, e.g., atmospheric dynamical patterns, extreme solar particle storms, long-term solar activity reconstruction from cosmogenic proxy data, solar-terrestrial relation.

\section{Code and data availability}

Since the SOCOL-AER code is based on ECHAM5, users must first sign the ECHAM5 license agreement before accessing the SOCOL-AER code (http://www.mpimet.mpg.de/en/science/models/license/). SOCOL-AER code is then freely available upon request from the authors, Beryllium module can be found at https://doi.org/10.5281/zenodo.4558738. The raw model data of this article can be available at https://doi.org/10.5281/zenodo.4559797. Beryllium data from vDEC database can be found at https://www.ctbto.org/specials/vdec/ and from STUK database at https://www.stuk.fi/web/en/services.

\section{Author contribution}

All authors participated in the model development, verification, discussions about the results, and revisions to the article. IU, GK and ER designed the the main idea of this study and KG carried them out. KG was supervised directly by ER and TS during the model code improvement work. APL find and prepared the real Beryllium data for the model verification. IU and $\mathrm{KG}$ data processing and figures preparation. IU prepared the manuscript.

\section{Disclaimer}

The views expressed here in are those of the authors and do not necessarily reflect the views of the CTBTO Preparatory Commission.

\section{Financial support}

345 This work was partly supported by the Academy of Finland (Projects ESPERA no. 321882) and the Vilho, Yrjö and Kalle Väisälä Foundation of the Finnish Academy of Science and Letters (K. Golubenko has been granted a scholarship for 2021). The SOCOL model development and maintenance were supported by the Swiss National Science Foundation under grants 200021-169241 (VEC) and 200020-182239 (POLE). I. Usoskin work on the experimental design and parameterization of 7Be and 10Be production was partially supported by the Russian Science Foundation (RSF Project No. 20-67-46016). E. Rozanov and T. Sukhodolov work on the model development was performed in the SPbSU "Ozone Layer and Upper Atmosphere Research Laboratory", which is supported by the Ministry of Science and Higher Education of the Russian Federation.

\section{Competing interests}

The authors declare that they have no conflict of interest. 
https://doi.org/10.5194/gmd-2021-56

Preprint. Discussion started: 7 April 2021

(C) Author(s) 2021. CC BY 4.0 License.

(c) (i)

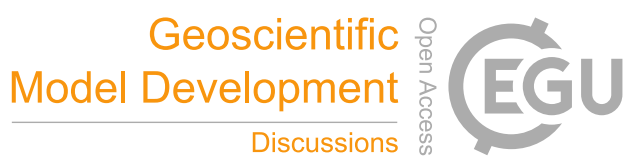

Acknowledgements. The authors would like to thank Weihua Zhang, Ian Hoffman and Kurt Ungar of the Radiation Protection Bureau

of Health Canada for providing the Yellowknife data. The authors acknowledge the work of CTBTO staff and CL18 and FRP30 station operating staff for producing and providing the corresponding data under a vDEC agreement (https://www.ctbto.org/specials/vdec/). KG thanks E. Rozanov for Fortran lessons, S. Poluyanov for ORAVA cluster setting, and M.V. Vokhmyanin for assistance in big data analysis. 
https://doi.org/10.5194/gmd-2021-56

Preprint. Discussion started: 7 April 2021

(c) Author(s) 2021. CC BY 4.0 License.

(c) (i)

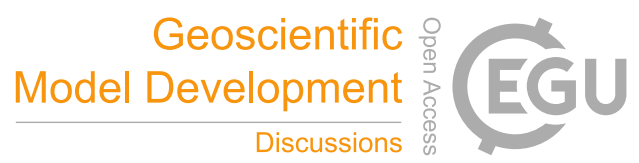

\section{References}

Beer, J., McCracken, K., von Steiger, R., 2012. Cosmogenic Radionuclides: Theory and Applications in the Terrestrial and Space Environments. Springer, Berlin.

Brattich, E., Orza, J.A.G., Cristofanelli, P., Bonasoni, P., Marinoni, A., Tositti, L., 2020. Advection pathways at the Mt. Cimone WMO-GAW station: Seasonality, trends, and influence on atmospheric composition. Atmos. Envir. $234,117513$. doi:https://doi.org/10.1016/j.atmosenv.2020.117513.

Butchart, N., 2014. The Brewer-Dobson circulation. Rev. Geophys. 52, 157-184. doi:https://doi.org/10.1002/2013RG000448.

Cohen, N., Gerber, E., Bühler, O., 2014. What Drives the Brewer-Dobson Circulation? J. Atmos. Sci. 71, 3837-3855. doi:https://doi.org/10.1175/JAS-D-14-0021.1.

Cooke, D., Humble, J., Shea, M., Smart, D., Lund, N., Rasmussen, I., Byrnak, B., Goret, P., Petrou, N., 1991. On cosmic-ray cut-off terminology. Nuovo Cimento C 14, 213-234.

Delaygue, G., Bekki, S., Bard, E., 2015. Modelling the stratospheric budget of beryllium isotopes. TELLUS SERIES B-CHEMICAL AND PHYSICAL METEOROLOGY 67, 28582. doi:https://doi.org/10.3402/tellusb.v67.28582.

Desai, M., Giacalone, J., 2016. Large gradual solar energetic particle events. Liv. Rev. Solar Phys. 13, 3. doi:https://doi.org/10.1007/s41116016-0002-5.

Dorman, L., 2004. Cosmic Rays in the Earth's Atmosphere and Underground. Kluwer Academic Publishers, Dordrecht.

Egorova, T., Rozanov, E., Zubov, V., Karol, I., 2003. Model for investigating ozone trends (mezon). Izvestiya - Atmos. Ocean Phys. 39, 375 277-292.

Emery, W., Camps, A., 2017. Introduction to Satellite Remote Sensing. Elsevier. URL: https://www.elsevier.com/books/ introduction-to-satellite-remote-sensing/emery/978-0-12-809254-5, doi:https://doi.org/10.1016/B978-0-12-809254-5.00008-7.

Feinberg, A., Sukhodolov, T., Luo, B.P., Rozanov, E., Winkel, L.E., Peter, T., Stenke, A., 2019. Improved tropospheric and stratospheric sulfur cycle in the aerosol-chemistry-climate model SOCOL-AERv2. Geosci. Model Devel. 12, 3863-3887. doi:https://doi.org/10.5194/gmd12-3863-2019.

Field, C., Schmidt, G., Koch, D., Salyk, C., 2006. Modeling production and climate-related impacts on ${ }^{10}$ be concentration in ice cores. J. Geophys. Res. 111, D15107.

Fraser-Smith, A.C., 1987. Centered and eccentric geomagnetic dipoles and their poles, 1600 - 1985. Rev. Geophys. 25, 1-16.

Geant4 collaboration, 2020. Physics reference manual (version Geant4 10.6.0). Available from https://geant4.web.cern.ch/ support.

Gleeson, L., Axford, W., 1968. Solar modulation of galactic cosmic rays. Astrophys. J. 154, 1011-1026. doi:https://doi.org/10.1086/149822.

Golubenko, K., Rozanov, E., Mironova, I., Karagodin, A., Usoskin, I., 2020. Natural Sources of Ionization and Their Impact on Atmospheric Electricity. Geophys. Res. Lett. 47, e88619. doi:https://doi.org/10.1029/2020GL088619.

Hauglustaine, D.A., Granier, C., Brasseur, G.P., MéGie, G., 1994. The importance of atmospheric chemistry in the calculation of radiative forcing on the climate system. J. Geophys. Res. 99, 1173-1186. doi:https://doi.org/10.1029/93JD02987.

Heck, D., Knapp, J., Capdevielle, J., Schatz, G., Thouw, T., 1998. Corsika: A monte carlo code to simulate extensive air showers, in: FZKA 6019. Forschungszentrum, Karlsruhe.

Heikkilä, U., Beer, J., Alfimov, V., 2008a. Beryllium-10 and beryllium-7 in precipitation in dübendorf (440 m) and at jungfraujoch (3580 m), switzerland (1998-2005). J. Geophys. Res. 113, D11104. URL: https://agupubs.onlinelibrary.wiley.com/doi/abs/10.1029/2007JD009160, doi:https://doi.org/10.1029/2007JD009160. 
https://doi.org/10.5194/gmd-2021-56

Preprint. Discussion started: 7 April 2021

(c) Author(s) 2021. CC BY 4.0 License.

(c) (i)

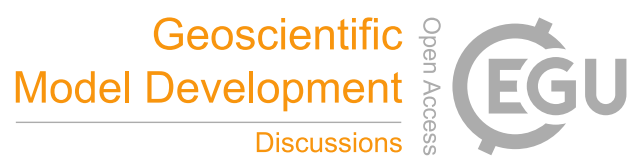

Heikkilä, U., Beer, J., Feichter, J., 2008b. Modeling cosmogenic radionuclides ${ }^{10} \mathrm{Be}$ and ${ }^{7} \mathrm{Be}$ during the Maunder Minimum using the ECHAM5-HAM General Circulation Model. Atmos. Chem. Phys. 8, 2797-2809. doi:https://doi.org/10.5194/acp-8-2797-2008.

Heikkilä, U., Beer, J., Feichter, J., 2009. Meridional transport and deposition of atmospheric ${ }^{10}$ Be. Atmos. Chem. Phys. 9, 515-527. doi:https://doi.org/10.5194/acp-9-515-2009.

Hommel, R., Timmreck, C., Graf, H.F., 2011. The global middle-atmosphere aerosol model MAECHAM5-SAM2: comparison with satellite and in-situ observations. Geosci. Model Develop. 4, 809-834. doi:https://doi.org/10.5194/gmd-4-809-2011.

Ioannidou, A., Paatero, J., 2014. Activity size distribution and residence time of ${ }^{7}$ Be aerosols in the Arctic atmosphere. Atmos. Env. 88, 99-106. doi:https://doi.org/10.1016/j.atmosenv.2013.12.046.

Jordan, C.E., Dibb, J.E., Finkel, R.C., 2003. ${ }^{10} \mathrm{Be} /{ }^{7}$ Be tracer of atmospheric transport and stratosphere-troposphere exchange. J. Geophys. Res. 108, 4234. doi:https://doi.org/10.1029/2002JD002395.

405 Kerkweg, A., Buchholz, J., Ganzeveld, L., Pozzer, A., Tost, H., Jöckel, P., 2006. Technical note: An implementation of the dry removal processes dry deposition and sedimentation in the modular earth submodel system (messy). Atmospheric Chemistry and Physics 6, 4617-4632. URL: https://acp.copernicus.org/articles/6/4617/2006/, doi:https://doi.org/10.5194/acp-6-4617-2006.

Kovaltsov, G., Usoskin, I., 2010. A new 3D numerical model of cosmogenic nuclide ${ }^{10}$ Be production in the atmosphere. Earth Planet.Sci.Lett. 291, 182-188.

410 Lal, D., Peters, B., 1967. Cosmic ray produced radioactivity on the earth, in: Sittle, K. (Ed.), Handbuch der Physik. Springer, Berlin. volume 46, pp. 551-612.

Leppänen, A., 2019. Deposition of naturally occurring $7 \mathrm{Be}$ and $210 \mathrm{~Pb}$ in Northern Finland. J. Environm. Radioact. 208-209, $105995 . \quad$ URL: http://www.sciencedirect.com/science/article/pii/S0265931X19301845, doi:https://doi.org/https://doi.org/10.1016/j.jenvrad.2019.105995.

415 Leppänen, A.P., Usoskin, I.G., Kovaltsov, G.A., Paatero, J., 2012. Cosmogenic ${ }^{7}$ Be and ${ }^{22}$ Na in Finland: Production, observed periodicities and the connection to climatic phenomena. J. Atmos. Solar-Terr. Phys. 74, 164-180. doi:https://doi.org/10.1016/j.jastp.2011.10.017.

Lin, S., Rood, R., 1996. Multidimensional flux-form semi-Lagrangian transport schemes. Mon. Weather Rev. 124, $2046-2070$.

McCracken, K., 2004. Geomagnetic and atmospheric effects upon the cosmogenic ${ }^{10}$ be observed in polar ice. J. Geophys. Res. 109. doi:https://doi.org/10.1029/2003JA010060.

Medici, F., 2001. Particulate sampling in the IMS radionuclide network of the Comprehensive-Nuclear Test Ban Treaty. Kerntechnik 66, $121-125$.

Miley, H., Bowyer, S., Hubbard, C., McKinnon, A., Perkins, R., Thompson, R., Warner, R., 1998. A description of the DOE Radionuclide Aerosol Sampler/Analyzer for the Comprehensive Test Ban Treaty. J. Radioanal. Nucl. Chem. 235, 83-87.

Mironova, I.A., Aplin, K.L., Arnold, F., Bazilevskaya, G.A., Harrison, R.G., Krivolutsky, A.A., Nicoll, K.A., Rozanov, E.V., Turunen, E., Usoskin, I.G., 2015. Energetic Particle Influence on the Earth's Atmosphere. Space Sci Rev. 194, 1-96. doi:https://doi.org/10.1007/s11214-015-0185-4.

Pacini, A.A., Usoskin, I.G., Evangelista, H., Echer, E., de Paula, R., 2011. Cosmogenic isotope ${ }^{7}$ Be: A case study of depositional processes in Rio de Janeiro in 2008-2009. Adv. Space Res. 48, 811-818. doi:https://doi.org/10.1016/j.asr.2011.04.035.

Pacini, A.A., Usoskin, I.G., Mursula, K., Echer, E., Evangelista, H., 2015. Signature of a sudden stratospheric warming in the near-ground

\footnotetext{
${ }^{7}$ Be flux. Atmos. Env. 113, 27-31. doi:https://doi.org/10.1016/j.atmosenv.2015.04.065.
} 
https://doi.org/10.5194/gmd-2021-56

Preprint. Discussion started: 7 April 2021

(c) Author(s) 2021. CC BY 4.0 License.

(c) (i)

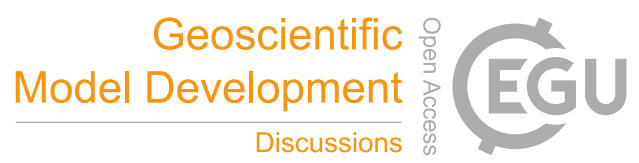

Poluianov, S., Kovaltsov, G.A., Mishev, A.L., Usoskin, I.G., 2016. Production of cosmogenic isotopes ${ }^{7} \mathrm{Be},{ }^{10} \mathrm{Be},{ }^{14} \mathrm{C},{ }^{22} \mathrm{Na}$, and ${ }^{36} \mathrm{Cl}$ in the atmosphere: Altitudinal profiles of yield functions. J. Geophys. Res. (Atm.) 121, 8125-8136. doi:https://doi.org/10.1002/2016JD025034, arXiv: 1606.05899 .

Raisbeck, G.M., Yiou, F., Fruneau, M., Loiseaux, J.M., Lieuvin, M., Ravel, J.C., 1981. Cosmogenic ${ }^{10}$ Be $/{ }^{7}$ Be as a probe of atmospheric transport processes. Geophys. Res. Lett. 8, 1015-1018. doi:https://doi.org/10.1029/GL008i009p01015.

Raukunen, O., Vainio, R., Tylka, A.J., Dietrich, W.F., Jiggens, P., Heynderickx, D., Dierckxsens, M., Crosby, N., Ganse, U., Siipola, R., 2018. Two solar proton fluence models based on ground level enhancement observations. J. Space Weather Space Clim. 8, A04. doi:https://doi.org/10.1051/swsc/2017031.

Revell, L., Stenke, A., Tummon, F., Feinberg, A., Rozanov, E., Peter, T., Abraham, N., Akiyoshi, H., Archibald, A., Butchart, N., Deushi, M., Jöckel, P., Kinnison, D., Michou, M., Morgenstern, O., O’Connor, F., Oman, L., Pitari, G., Plummer, D., Schofield, R., Stone, K., Tilmes, S., Visioni, D., Yamashita, Y., Zeng, G., 2018. Tropospheric ozone in CCMI models and Gaussian process emulation to understand biases in the SOCOLv3 chemistry-climate model. Atmos. Chem. Phys. 18, 16155-16172. doi:https://doi.org/10.5194/acp-18-16155-2018.

Steinhilber, F., Abreu, J., Beer, J., Brunner, I., Christl, M., Fischer, H., Heikkilae, U., Kubik, P., Mann, M., McCracken, K., Miller, H., Miyahara, H., Oerter, H., Wilhelms, F., 2012. 9,400 years of cosmic radiation and solar activity from ice cores and tree rings. Proc. Nat. Acad. Sci. USA 109, 5967-5971. doi:https://doi.org/10.1073/pnas.1118965109.

Stenke, A., Schraner, M., Rozanov, E., Egorova, T., Luo, B., Peter, T., 2013. The SOCOL version 3.0 chemistry-climate model: description, evaluation, and implications from an advanced transport algorithm. Geosci. Model Develop. 6, 1407-1427. doi:https://doi.org/10.5194/gmd-6-1407-2013.

Sukhodolov, T., Usoskin, I., Rozanov, E., Asvestari, E., Ball, W., Curran, M., Fischer, H., Kovaltsov, G., Miyake, F., Peter, T., Plummer, C., Schmutz, W., Severi, M., Traversi, R., 2017. Atmospheric impacts of the strongest known solar particle storm of 775 AD. Sci. Rep. 7 , 45257. doi:https://doi.org/10.1038/srep45257.

Thébault, E., Finlay, C.C., Beggan, C.D., Alken, P., Aubert, J., Barrois, O., Bertrand, F., Bondar, T., Boness, A., Brocco, L., Canet, E., Chambodut, A., Chulliat, A., Coïsson, P., Civet, F., Du, A., Fournier, A., Fratter, I., Gillet, N., Hamilton, B., Hamoudi, M., Hulot, G., Jager, T., Korte, M., Kuang, W., Lalanne, X., Langlais, B., Léger, J.M., Lesur, V., Lowes, F.J., Macmillan, S., Mandea, M., Manoj, C., Maus, S., Olsen, N., Petrov, V., Ridley, V., Rother, M., Sabaka, T.J., Saturnino, D., Schachtschneider, R., Sirol, O., Tangborn, A., Thomson, A., Tøffner-Clausen, L., Vigneron, P., Wardinski, I., Zvereva, T., 2015. International Geomagnetic Reference Field: the 12th generation. Earth Planets Space 67, 79. doi:https://doi.org/10.1186/s40623-015-0228-9.

Tost, H., Lawrence, M.G., Brühl, C., Jöckel, P., Gabriel Team, Scout-O3-Darwin/Active Team, $2010 . \quad$ Uncertainties in atmospheric chemistry modelling due to convection parameterisations and subsequent scavenging. Atmos. Chem. Phys. 10, 1931-1951. doi:https://doi.org/10.5194/acp-10-1931-2010.

Usoskin, I., Koldobskiy, S., Kovaltsov, G., Rozanov, E., Sukhodolov, T., Mishev, A., Mironova, I., 2020a. Revisited Reference Solar Proton Event of 23 February 1956: Assessment of the Cosmogenic-Isotope Method Sensitivity to Extreme Solar Events. J. Geophys. Res. (Space Phys.) 125, e27921. doi:https://doi.org/10.1029/2020JA027921, arXiv:2005.10597.

Usoskin, I., Koldobskiy, S., Kovaltsov, G.A., Gil, A., Usoskina, I., Willamo, T., Ibragimov, A., 2020b. Revised GLE database: Fluences of solar energetic particles as measured by the neutron-monitor network since $1956 . \quad$ Astron. Astrophys. 640, A17. doi:https://doi.org/10.1051/0004-6361/202038272.

Usoskin, I., Kovaltsov, G., 2008. Production of cosmogenic ${ }^{7}$ Be isotope in the atmosphere: Full 3D modelling. J. Geophys. Res. 113, "D12107". doi:https://doi.org/10.1029/2007JD009725. 
https://doi.org/10.5194/gmd-2021-56

Preprint. Discussion started: 7 April 2021

(c) Author(s) 2021. CC BY 4.0 License.

(c) (i)

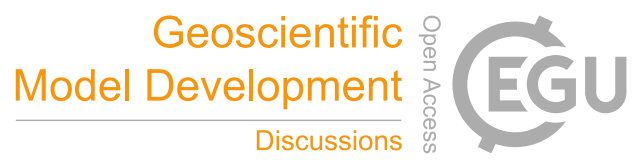

Usoskin, I., Solanki, S., Kovaltsov, G., Beer, J., Kromer, B., 2006. Solar proton events in cosmogenic isotope data. Geophys. Res. Lett. 33,

L08107. doi:https://doi.org/10.1029/2006GL026059.

Usoskin, I.G., Field, C.V., Schmidt, G.A., Leppänen, A.P., Aldahan, A., Kovaltsov, G.A., Possnert, G., Ungar, R.K., 2009a. Short-term production and synoptic influences on atmospheric ${ }^{7} \mathrm{Be}$ concentrations. J. Geophys. Res. 114 , D06108. doi:https://doi.org/10.1029/2008JD011333.

Usoskin, I.G., Gil, A., Kovaltsov, G.A., Mishev, A.L., Mikhailov, V.V., 2017. Heliospheric modulation of cosmic rays during the neutron monitor era: Calibration using PAMELA data for 2006-2010. J. Geophys. Res. (Space Phys.) 122, 3875-3887. doi:https://doi.org/10.1002/2016JA023819, arXiv:1705.07197.

Usoskin, I.G., Horiuchi, K., Solanki, S., Kovaltsov, G.A., Bard, E., 2009b. On the common solar signal in different cosmogenic isotope data sets. J. Geophys. Res. 114, A03112. doi:https://doi.org/10.1029/2008JA013888.

Usoskin, I.G., Mironova, I.A., Korte, M., Kovaltsov, G.A., 2010. Regional millennial trend in the cosmic ray induced ionization of the troposphere. J. Atmos. Solar-Terrest. Phys. 72, 19-25. doi:https://doi.org/10.1016/j.jastp.2009.10.003.

Vainio, R., Desorgher, L., Heynderickx, D., Storini, M., Flückiger, E., Horne, R.B., Kovaltsov, G.A., Kudela, K., Laurenza, M., McKennaLawlor, S., Rothkaehl, H., Usoskin, I.G., 2009. Dynamics of the Earth's particle radiation environment. Space Sci. Rev. 147, $187-231$. doi:https://doi.org/10.1007/s11214-009-9496-7.

Weisenstein, D.K., Yue, G.K., Ko, M.K.W., Sze, N.D., Rodriguez, J.M., Scott, C.J., 1997. A two-dimensional model of sulfur species and aerosols. Journal of Geophysical Research: Atmospheres 102, 13019-13035. doi:https://doi.org/10.1029/97JD00901.

Wesely, M.L., 1989. Parameterization of surface resistances to gaseous dry deposition in regional-scale numerical models. Atmos. Env. 23, 1293-1304. doi:https://doi.org/10.1016/0004-6981(89)90153-4.

Wu, C.J., Usoskin, I.G., Krivova, N., Kovaltsov, G.A., Baroni, M., Bard, E., Solanki, S.K., $2018 . \quad$ Solar activity over nine millennia: A consistent multi-proxy reconstruction. Astron. Astrophys. 615, A93. doi:https://doi.org/10.1051/0004-6361/201731892, arXiv: 1804.01302 .

Zheng, M., Sjolte, J., Adolphi, F., Aldahan, A., Possnert, G., Wu, M., Muscheler, R., 2021. Solar and meteorological influences on seasonal atmospheric 7Be in Europe for 1975 to 2018. Chemosphere 263, 128318. URL: http://www.sciencedirect.com/science/article/pii/ S0045653520325133, doi:https://doi.org/https://doi.org/10.1016/j.chemosphere.2020.128318. 


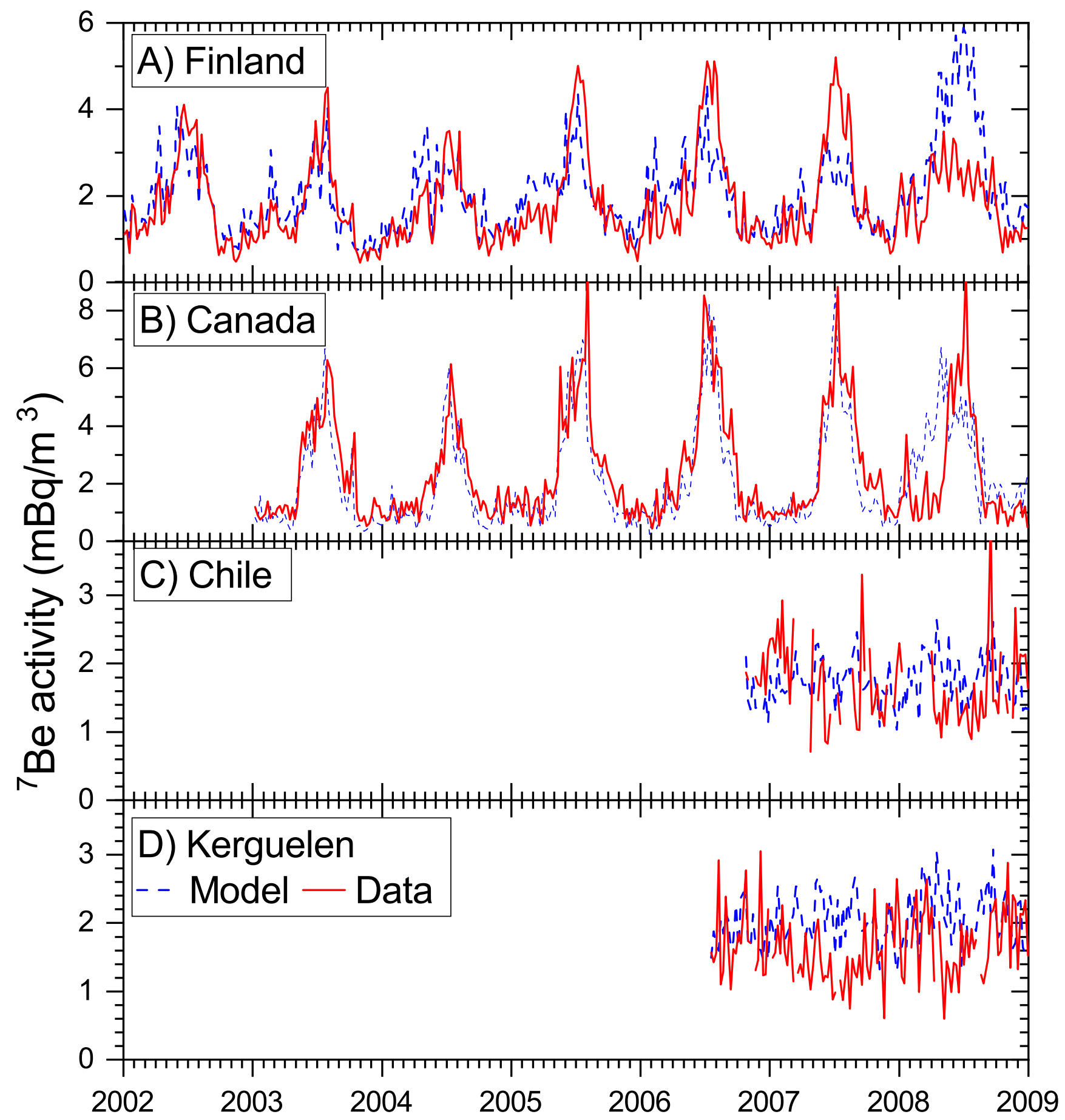

Figure 8. Datasets of ${ }^{7} \mathrm{Be}$ activity concentrations in the near-ground air used in this study, including (panels A through D respectively) Finland (a composite of four stations), Yellowknife (Canada), Punta Arenas (Chile), and Kerguelen island (France). The measured and modelled activities are shown as solid red and dashed blue curves, respectively. 


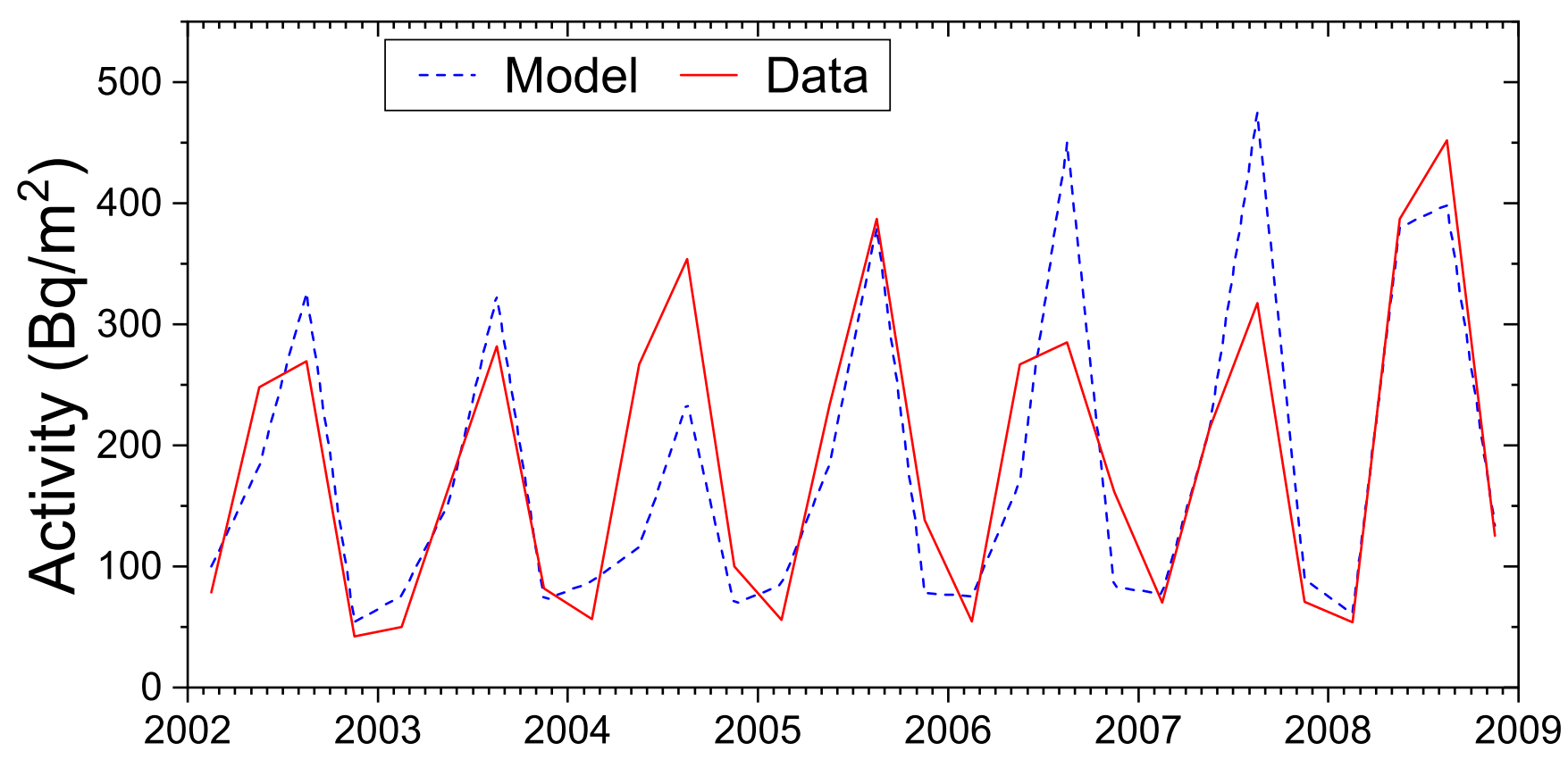

Figure 9. Quarterly-averaged total deposition of ${ }^{7} \mathrm{Be}$ in northern Finland stations for the period $2002-2008$. The blue dashed line represents the total modelled deposition, while the red line depicts the measured data. 

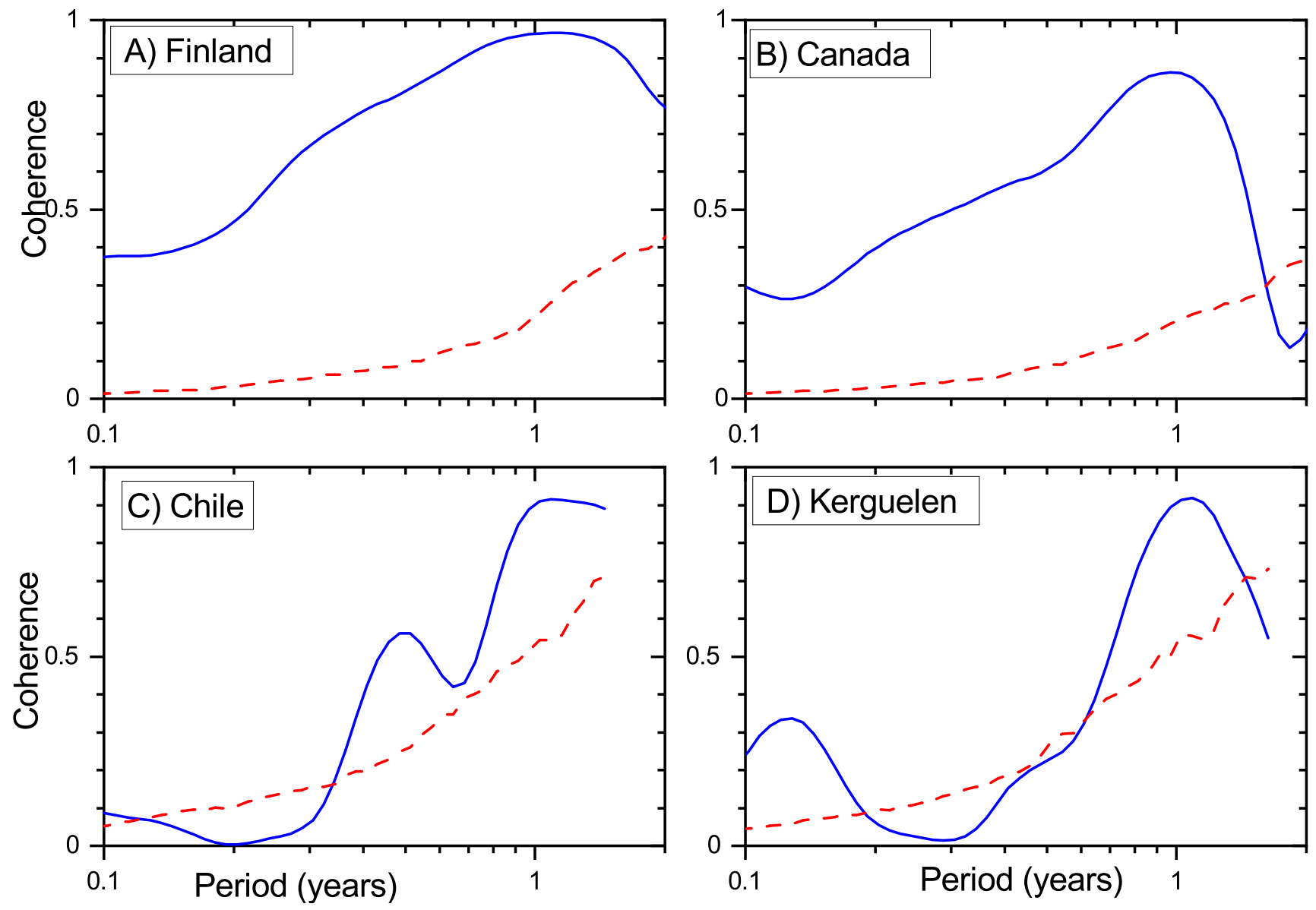

Figure 10. Global wavelet coherence (Morlet base, $k=3$ ) between modelled and measured ${ }^{7}$ Be activity for the four locations considered here. The red dashed line denotes the $95 \%$ confidence level against the AR(1) red noise. 